\title{
Conference Report: The IEEE Colombian Conference on Automatic Control 2017
}

The $3^{\text {th }}$ IEEE Colombian Conference on Automatic Control 2017 (CCAC) was held October 18-20th, 2017 at the Corales de Indias Hotel, Cartagena de Indias, Colombia. The conference was preceded by a day devoted to four technical workshops.

CCAC is the main gathering for Colombian researchers, and it has begun to attract researchers from many different Latin American institutions. CCAC has been the main control conference in the country since 2011, one year after the IEEE CSS Colombian Chapter was founded. The conference is held in odd years, and previous meetings of CCAC were held in Bogotá (2011) and Manizales (2015). This was the first time it was organized in Cartagena de Indias, a small piece of paradise in the Colombian Caribbean coast. The 2017 CCAC was, for the first time, sponsored by the IEEE Control Systems Society (CSS), which highlights the quality of the event. CCAC also received support from the CSS Outreach Program, which provided funds to support students and travel for external keynote speakers.

An organizing committee coordinated the technical aspects of CCAC, chaired by C. Ocampo-Martinez and J. Villa and complemented by D. Patiño (Program and Publications Chair), N. Quijano (Program Vice-chair for Control Systems), J. Colorado (Program ViceChair for Robotics), F. Ruiz (Workshops and Local Arrangement Chair), J. García-Tirado (Publicity Chair), E. Mojica-Nava (Awards Chair), G. Osorio (Poster Sessions Chair), and the IEEE Colombian Section (Finance chairing).

The CCAC was well attended and had the largest number of registrants to date, with a total of 146 attendees, compared to approximately 70 in 2015.

\section{Technical Program}

The conference aims to disseminate new knowledge and developments in robotics, control theory, and applications that have been performed in Colombia, Latin America, and by Colombian researchers overseas. CCAC also aims to create a community of Colombian and Latin American researchers, to promote networking and dynamic interaction with leading researchers worldwide, especially within the CSS (at both the Colombian and international levels).

Seven leading researchers (both foreign and national) in the automatic control field were invited to give interesting talks, including: A. Nedich (ASU) on "Distributed Systems: Optimization and Learning;" J. Moreno (UNAM) on "Observation and Control of Nonlinear Systems: A Homogeneity Approach;" R. Sánchez-Peña (ITBA) on "First Artificial Pancreas Clinical Tests in Latin America;" C. Rossi (UPM), on "Gear-less and Motor-less Robots at the Bio-Inspired Systems Lab;" H. Álvarez (UNAL Medellín), on "From Process Modeling to its Control;" A. Pantoja (UN), on "Control Applications in Smart Grids: Case Studies in the ALTERNAR Project;" and H. Díaz (UNAL Bogotá), on "Parameter Estimation for a Synchronous Generator." 
In addition to the workshops, the technical program also included 20 regular sessions grouped into five main slots, including topics such as: modeling of dynamic systems; sensing and sensor fusion; process optimization; control of mechatronic systems; renewable energy and microgrids; control of chemical processes; control of power systems; mobile robotics; system identification and estimation; control of biological systems; and industrial applications. To encourage active participation of bachelor's- and master's-level students, three poster sessions were also organized, with 26 contributed posters. The ongoing work of $14 \mathrm{Ph}$.D. students were also presented in a poster session. A total of 85 papers were presented at the conference (out of 160 submitted), which implies an acceptance rate of 53\%. This is lower than in previous years (75\% for 2011 and $60 \%$ for 2015), which is consistent with the commitment to improve the CCAC quality.

\section{Workshops}

The conference was preceded by four half-day workshops taught by international and national experts in each area. A total of 25 people attended, all of them students eager to learn new topics. The workshops were: "A Treatment for Type-1 Diabetes Mellitus from Control Engineering," organized by R. Sánchez-Peña (ITBA) and J. García-Tirado (ITM); "Aerial Robotics: Foundations and Applications," organized by J. Colorado and I. Mondragón (PUJ); "Distributed Optimization: from Consensus to Learning," organized by C. Uribe (University of Illinois at Urbana-Champaign) and E. Mojica-Nava (UNAL Bogotá); and "Hybrid Dynamical Systems: From Modeling and Stability Theory to Applications in Machine Learning, Engineering, and Finance," organized by J. Poveda (UCSB).

\section{Awards}

The CCAC closing ceremony was accompanied by the awards session. These awards included Best Student Paper, Best IEEE CSS Student Branch, and the Alain Gauthier Award. The Best Student Paper award recognizes the paper that obtains an average score of at least 2 out of 3 in the review process and is accompanied by an outstanding presentation. Seven papers were selected based on the review process, but only two of them obtained high scores during the presentations. The award was given to Javier José González, Cristian Lozano, and N. Quijano for the paper entitled "Social SCADA and Microgrid Prototype: La Guajira."

The IEEE CSS Student Branch Award was created to recognize the activities developed by an active IEEE CSS student branch worldwide. The award was given to the Universidad de los Andes, Colombia, IEEE Student branch. Mr. G. Riaño-Briceño received the prize for the outstanding social contributions of the branch in the past year. The Alain Gauthier Award is given to an outstanding professor or engineer who has made significant contributions in education, research, or projects within the country. This year, the award was given to J.M. Ramírez (UniValle, Cali), for his contributions in education within control theory and applications.

\section{Social Events}


Social events during the CCAC included a cocktail party at the end of the first day and a tour of the city ("Chiva Tour") at the end of the second day.

\section{Acknowledgements}

This conference and the workshops organized in Colombia in the control systems area have always been supported by the IEEE CSS Outreach Fund. We are indebted to the late Prof. Gary Balas for the support provided while he was the chair of this initiative, and also Prof. Daniel Rivera, President Edwin Chong, and all members of the IEEE CSS Board of Governors for all of the support.

\section{Next Conference}

The $4^{\text {th }}$ IEEE CCAC will be in Medellín, Colombia October $15-18^{\text {th }}, 2019$. The organizing committee will be led by H. Alvarez, D. Muñoz, and J. García-Tirado. More information is available at http://www.ieeeccac2019.com.

\section{Final Remarks}

Reaching this point where we have to summarize the highlights of conference has not been a trivial task. This required almost two years to prepare all the details, from simple logistics to obtaining highly recognized professors and researchers as keynote speakers. This required hundreds of hours of selfless work to provide a top-quality event. An important part of these efforts was focused on endowing the conference with more international impact by means of satisfying certain standards from IEEE, both in the technical program and its organization and logistics. The registration and local arrangements were excellently coordinated by Mrs. Angie Rueda, who also led a group of six student volunteers: Daniela Torres, Luis Eduardo Graterol, Bladimir de la Espriella, Ray Villareal, Miguel Jiménez, and Carolina Martínez.

C. Ocampo-Martinez

D. Patiño

N. Quijano 


\section{Pictures}

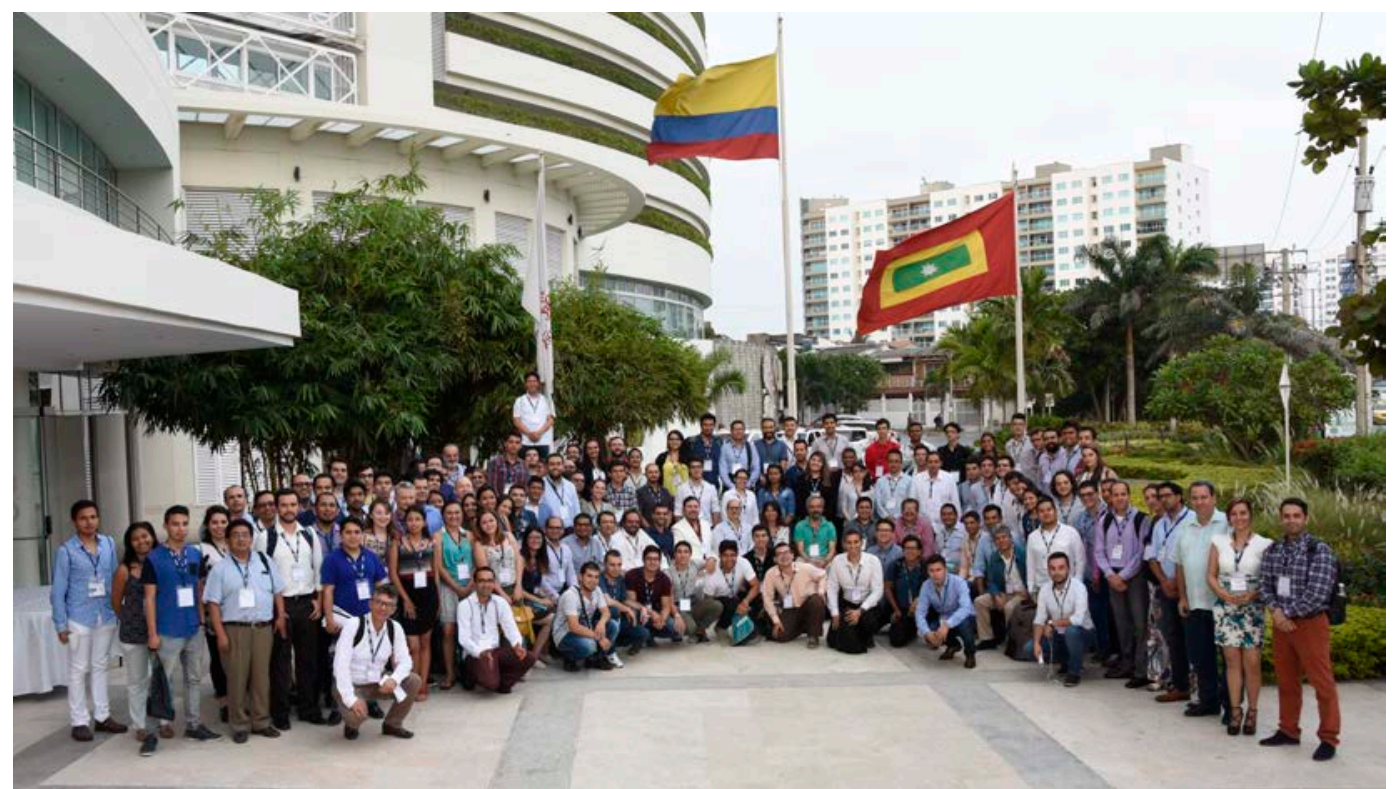

Figure 1: First day of the conference, with most of the attendees and organizers at the entrance of the Corales de Indias Hotel.

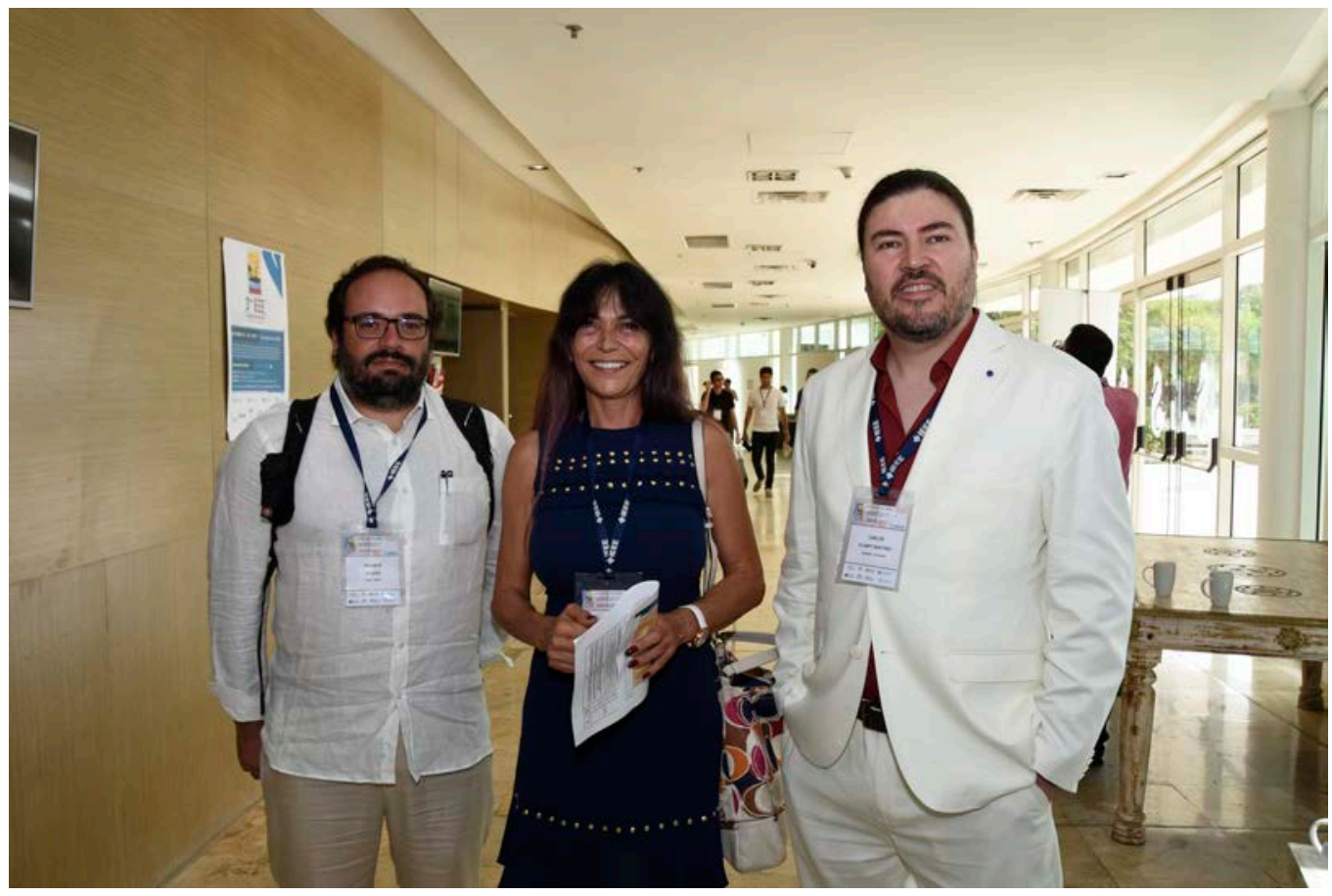

Figure 2: Opening activities and preliminary talk by Prof. Nedich (from left): Nicanor Quijano, Angelia Nedich, and Carlos Ocampo-Martinez. 


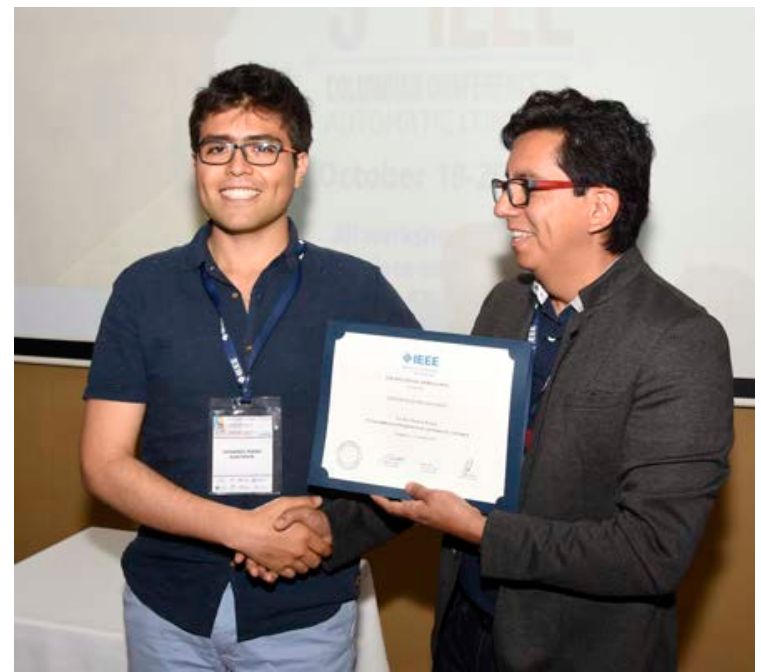

Figure 3: The IEEE CSS Student Branch Award delivered, to G. Riaño-Briceño (UniAndes) by the Awards Chair E. Mojica-Nava.

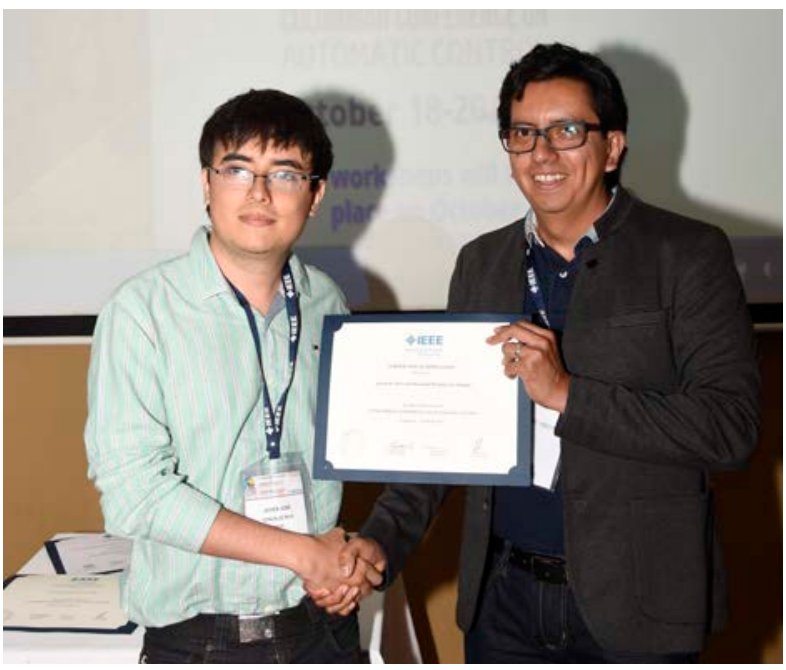

Figure 4: Best Student Paper Award, delivered to J. González by the Awards Chair E. Mojica-Nava.

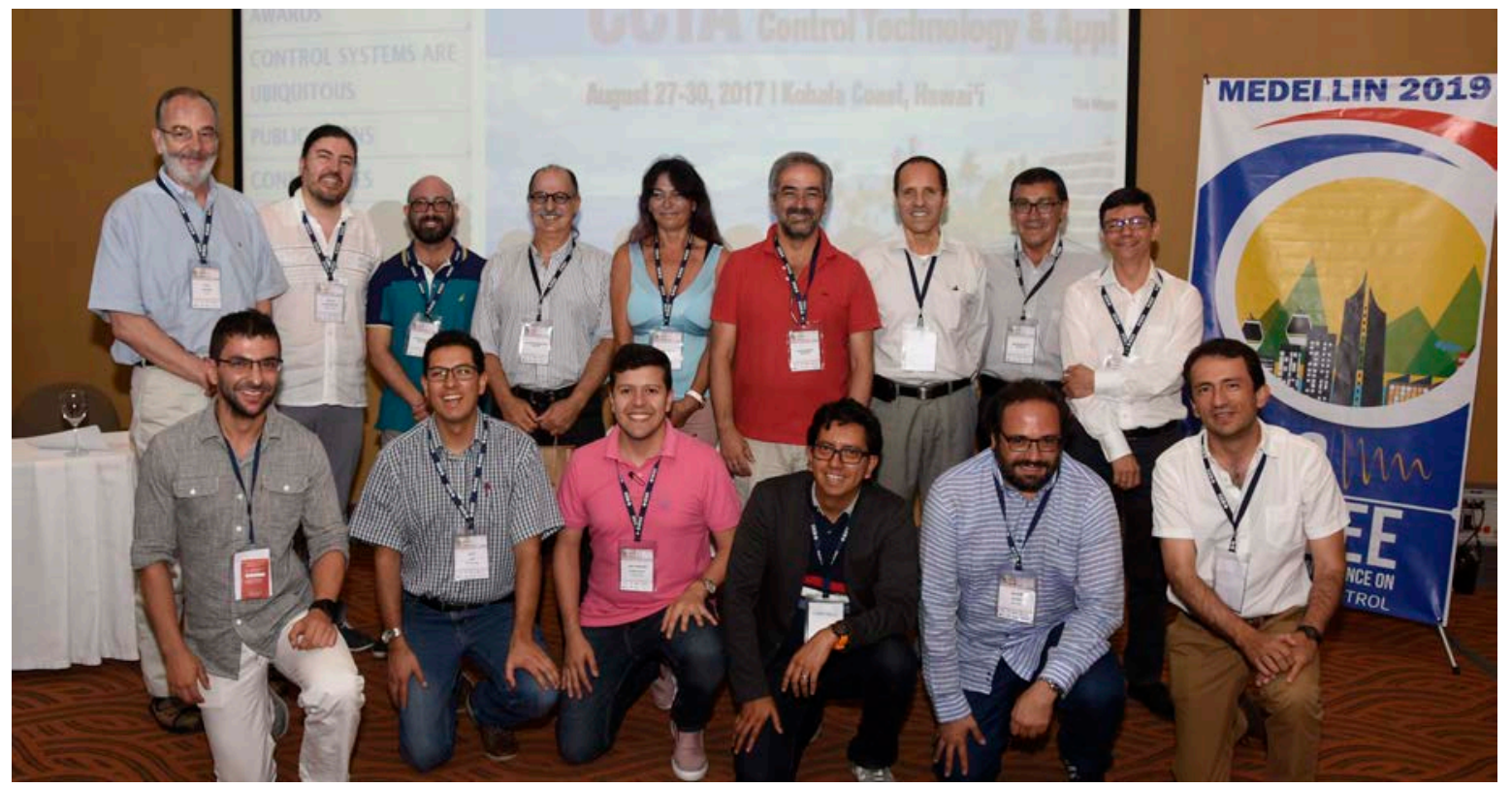

Figure 5: After the closing ceremony. Front row (from letf): Diego Patiño (Program Chair), Freddy Ruiz (Workshops Chair), José García-Tirado (Publicity Chair), Eduardo Mojica-Nava (Awards Chair), Nicanor Quijano (Program Vice-Chair of Control Systems), Gustavo Osorio (Poster Sessions Chair). Back row (from left): Alain Gauthier, Carlos Ocampo-Martinez (General Co-chair), Andrés Pantoja (Keynote Speaker), Ricardo Sánchez-Peña (Keynote Speaker), Angelia Nedich (Keynote Speaker), Jaime Moreno (Keynote Speaker), Hernán Álvarez (Keynote Speaker and General Chair of IEEE CCAC 2019), Hernando Díaz (Keynote Speaker), and José Villa (General Co-chair). 


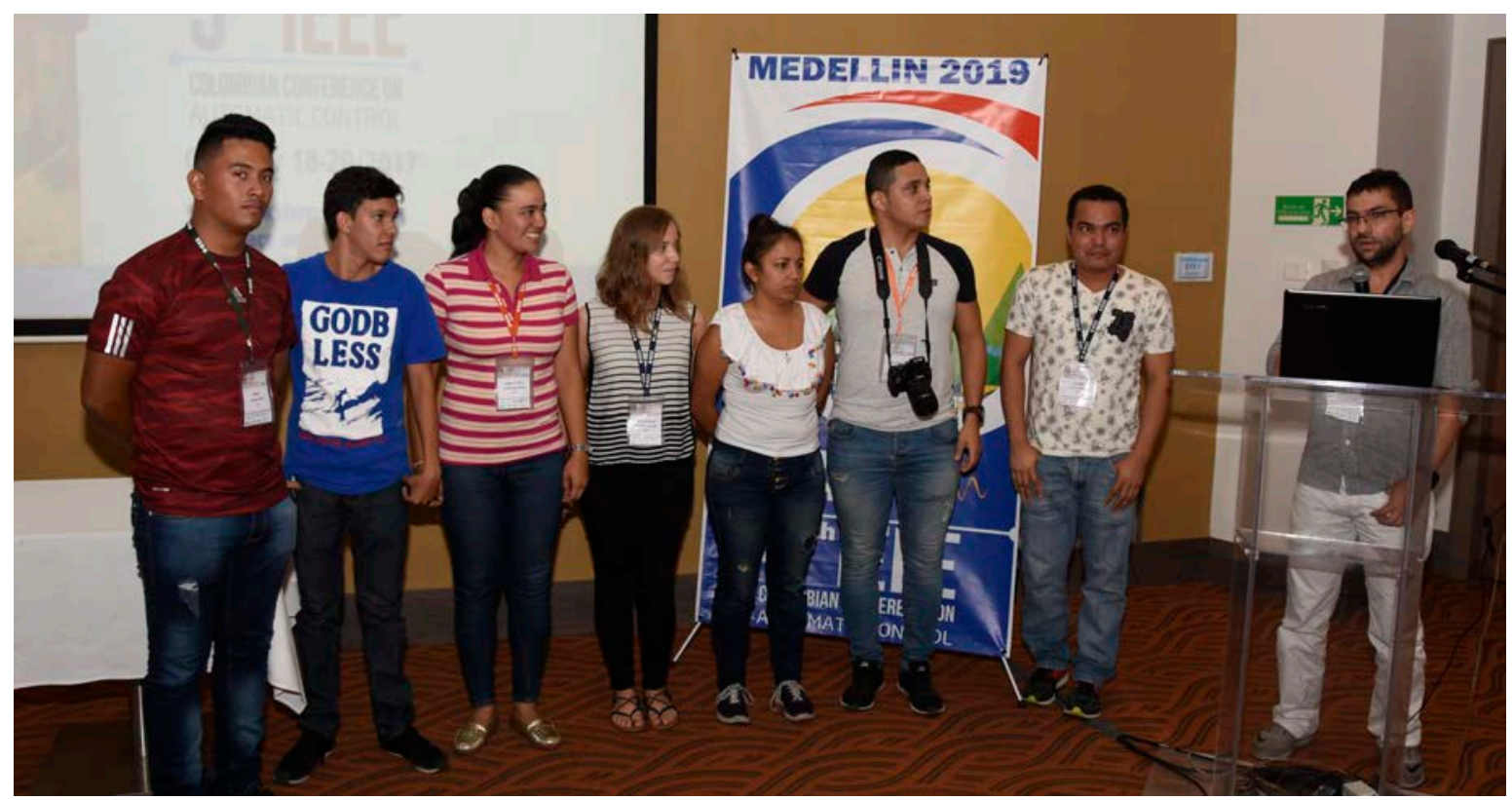

Figure 6: Diego Patiño (right) and the hard-working volunteers, led by Angie Rueda from the IEEE Colombia Section (fifth from left). 